\title{
Indices of intact serum parathyroid hormone and renal excretion of calcium, phosphate, and magnesium
}

\author{
N J Shaw, J Wheeldon, J T Brocklebank
}

\begin{abstract}
Up to date reference ranges were established for fasting renal excretion of calcium, phosphorus, and magnesium on 101 healthy children aged 2-15 years. A normal range for intact parathyroid hormone was also measured.

The indices of calcium and magnesium excretion showed no correlation with age or sex so that a common range for all children could be established. The 97th centile values for urinary calcium:creatinine and magnesium:creatinine ratios were $0.69 \mathrm{mmol}: \mathrm{mmol}$ and $1.05 \mathrm{mmol}: \mathrm{mmol}$ respectively. The calculated tubular maximum for phosphate/litre of glomerular filtrate $\left(\mathrm{TmPO}_{4} / \mathrm{GFR}\right)$ showed no correlation with age with a geometric mean value of $1.67 \mathrm{mmol} / \mathrm{l}$.

The normal range for intact serum parathyroid hormone for the age group was 11-35 $\mathrm{ng} / \mathrm{l}$, which is lower than the adult normal range using the same assay. There was an inverse correlation between $\mathrm{TmPO}_{4} / \mathrm{GFR}$ and intact parathyroid hormone in this group of normal children.
\end{abstract}

Investigation of disorders of mineral metabolism in children require reference to recognised normal ranges. Measurements of the renal handling of calcium, phosphorus, and magnesium are important in the elucidation of such disorders. Assessment of renal calcium handling is necessary in determining the contribution made by the kidney to hypocalcaemia and hypercalcaemia. In addition hypercalciuria is recognised not only as a risk factor for renal calculi but may also be a factor in a variety of other symptoms related to the urinary tract in children. ${ }^{1}$

Measurement of the renal tubular handling of phosphorus is necessary in the investigation of hypophosphataemia, which may be due to a primary renal tubular defect or secondary to a disturbance of parathyroid hormone function. Similarly, investigation of hypomagnesaemia in children, although rare, relies on measurement of urinary magnesium excretion to distinguish between a selective defect in intestinal absorption or a renal tubular leak. An accurate measurement of parathyroid hormone can also be of help in the investigation of such disorders.

Data available from different populations or different decades may not be applicable because of racial differences and changes in diet that occur with time. ${ }^{2}$ Normal values for parathyroid hormone concentration in serum have also changed because of the development of sensitive assays for the intact molecule in recent years. It was with the aim of producing reliable up to date reference ranges in British children that this study was undertaken.

\section{Patients and methods}

Urine samples were collected from 101 healthy children aged 2 to 15 years who had been fasted for at least 10 hours overnight before day case surgery. These samples were the second urine sample passed in the morning - that is, the first specimen after the overnight urine had been passed. A venous blood sample was collected at the same time with minimal venous stasis. The children were all ambulant before the samples being obtained and none was taking drugs known to affect the urinary excretion of calcium, phosphorus, or magnesium. The study was approved by the Leeds Eastern Health Authority ethical committee.

Plasma and urine calcium and magnesium were analysed by atomic absorption spectrophotometry. Creatinine was analysed by a kinetic Jaffé method and phosphate using ammonium molybdate in both urine and serum with a Beckmann Astra 8. Sufficient blood was simultaneously obtained from 78 children, stored at $4^{\circ} \mathrm{C}$ until clotted, and subsequently serum stored at $-20^{\circ} \mathrm{C}$ for later measurement of parathyroid hormone. Intact parathyroid hormone was measured using a two site immunoradiometric assay (PTH-Allegro).

The following indices were calculated. Fasting calcium and magnesium excretions were expressed as the ratio of their concentrations to the creatinine concentration in urine. In addition they were expressed as fasting calcium and magnesium excretion indices, which allow for variation in renal function, calculated by multiplying the ratio of urinary calcium or magnesium to creatinine concentration by the plasma creatinine to give values in $\mu \mathrm{mol} /$ litre of glomerular filtrate. ${ }^{3}$

The renal tubular handling of phosphorus was expressed as the tubular maximum reabsorption rate of phosphate per litre of glomerular filtrate $\left(\mathrm{TmPO}_{4} / \mathrm{GFR}\right)^{4}$ using the computer calculated formula based on Bijvoet's data. ${ }^{5}$ As the data were not normally distributed centiles were calculated for the indices of calcium and magnesium excretion and serum parathyroid hormone concentrations. The data for $\mathrm{TmPO}_{4} /$ GFR were expressed as geometric means and $\mathbf{9 5 \%}$ tolerance limits for different age groups. Correlations were performed after the data had been logarithmically transformed to produce normal distributions. 


\section{Results}

All the children studied had normal values for plasma calcium, magnesium, phosphate, and creatinine. The calculated indices of fasting calcium and magnesium excretion showed no association with age or sex and demonstrated an approximately $\log$ normal distribution (fig 1). The results of both sexes were therefore pooled and centiles calculated for the age group studied (table 1). A strong positive correlation was seen between the calcium:creatinine ratio and the calcium excretion index in this group of children with normal renal function $(r=0.97$, $\mathrm{p}<0.001$ ). A similar correlation exists between the magnesium:creatinine ratio and the magnesium excretion index. A positive correlation was also observed between the calcium:creatinine ratio and the magnesium:creatinine ratio $(\mathrm{r}=0.3, \mathrm{p}=0.004)$.

The values for $\mathrm{TmPO}_{4} / \mathrm{GFR}$ demonstrated no correlation with age. No difference in values was observed between the boys and girls. The data has been expressed as geometric means and $\mathbf{9 5 \%}$ tolerance limits for different age groups (table 2). As there was no correlation with age in this group of children, however, the geometric mean and $95 \%$ tolerance limits for the whole group are also given. A similar range is seen if centiles are calculated.

The values for intact parathyroid hormone also showed no association with age or sex so that a common normal range was calculated for the age group 2-15 years, which has again been represented as centiles (table 3 ). The association between parathyroid hormone and

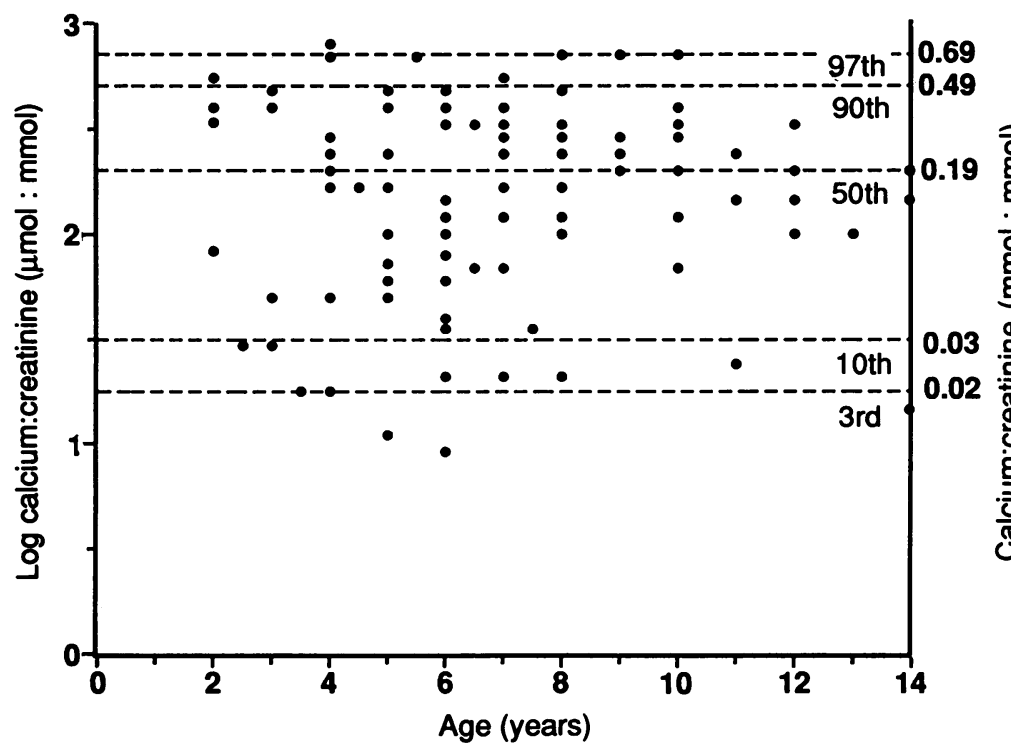

Figure 1 Values for calcium:creatinine ratio on 101 children aged 2-15 years depicted on a logarithmic scale indicating the centiles.
Table 2 Normal values for $\mathrm{TmPO}_{4} / G F R$ by age

\begin{tabular}{lll}
\hline Age (years) & $\begin{array}{l}\text { Geometric mean } \\
(\text { mmolll })\end{array}$ & $\begin{array}{l}\text { Tolerance limits } \\
(\mathrm{mmol} / \mathrm{l})\end{array}$ \\
\hline $2-3.9$ & 1.70 & $1 \cdot 04-2 \cdot 79$ \\
$4-5.9$ & 1.66 & $1.05-2 \cdot 60$ \\
$6-7.9$ & 1.72 & $1 \cdot 26-2 \cdot 35$ \\
$8-9.9$ & 1.59 & $1 \cdot 1-2 \cdot 31$ \\
$10-11.9$ & 1.72 & $1 \cdot 15-2 \cdot 58$ \\
$12-14.9$ & 1.57 & $1 \cdot 18-2 \cdot 09$ \\
$2-15$ & 1.67 & $1 \cdot 15-2 \cdot 44$ \\
\hline
\end{tabular}

Table 3 Normal values for intact parathyroid hormone

\begin{tabular}{ll}
\hline Centile & $\begin{array}{l}\text { Parathyroid hormone } \\
(\text { ng/l) }\end{array}$ \\
\hline 3 & $11 \cdot 0$ \\
10 & $12 \cdot 0$ \\
50 & $18 \cdot 5$ \\
90 & $29 \cdot 0$ \\
97 & $35 \cdot 0$ \\
\hline
\end{tabular}

$\mathrm{TmPO}_{4} / \mathrm{GFR}$ was examined and a significant inverse correlation was found $(r=-0.31$, $p=0.04)$ in this population of normal children (fig 2). There was no significant correlation seen between parathyroid hormone and the calcium:creatinine ratio $(r=-0.03, p=0.86)$ or the magnesium:creatinine ratio $(r=-0.21$, $p=0 \cdot 17)$.

\section{Discussion}

Our study presents normal values for urinary calcium and magnesium excretion in British children and in addition values for the tubular maximum reabsorption threshold of phosphate and the concentration of intact parathyroid hormone in serum for which data in this group have not previously been available.

There have been several other studies that have quoted normal ranges for urinary calcium and magnesium excretion in children, ${ }^{6-9}$ but the values presented have varied making it difficult to define what is abnormal. Calcium and magnesium excretions can be assessed either by a 24 hour urine collection or more simply by the ratio to creatinine in a single urine sample. It is generally accepted that the upper limit of normal for 24 hour urine calcium is $0.1 \mathrm{mmol} / \mathrm{kg} /$ day. ${ }^{6}$ A previous study on British children investigated in the 1970s demonstrated a good correlation between the 24 hour urinary calcium and the calcium:creatinine ratio of the second morning urine obtained in the fasting state, the latter demonstrating the least variation. ${ }^{6}$ The upper limit of normal for fasting calcium: creatinine ratio in that study was $0.74 \mathrm{mmol}$ : mmol. This result differs from several other published studies. Stapleton et al obtained fasting urine samples on $\mathbf{4 8}$ healthy American children aged 3 to 16 years after five days on a diet

Table 1 Centiles for indices of fasting calcium and magnesium excretion

\begin{tabular}{|c|c|c|c|c|}
\hline Centile & $\begin{array}{l}\text { Calcium:creatinine } \\
\text { (mmol:mmol) }\end{array}$ & $\begin{array}{l}\text { Magnesium:creatinine } \\
\text { (mmol:mmol) }\end{array}$ & $\begin{array}{l}\text { Calcium excretion index } \\
\text { ( } \text { molll glomerular filtrate) }\end{array}$ & $\begin{array}{l}\text { Magnesium excretion index } \\
\text { ( } \mu \text { moll/ glomerular filtrate) }\end{array}$ \\
\hline $\begin{array}{r}3 \\
10 \\
50 \\
90 \\
97\end{array}$ & $\begin{array}{l}0.02 \\
0.03 \\
0.19 \\
0.49 \\
0.69\end{array}$ & $\begin{array}{l}0.18 \\
0.22 \\
0.41 \\
0.69 \\
1.05\end{array}$ & $\begin{array}{r}1 \cdot 0 \\
1.4 \\
9 \cdot 1 \\
21 \cdot 9 \\
34 \cdot 8\end{array}$ & $\begin{array}{r}5.5 \\
10 \cdot 4 \\
18.4 \\
32 \cdot 2 \\
49 \cdot 3\end{array}$ \\
\hline
\end{tabular}




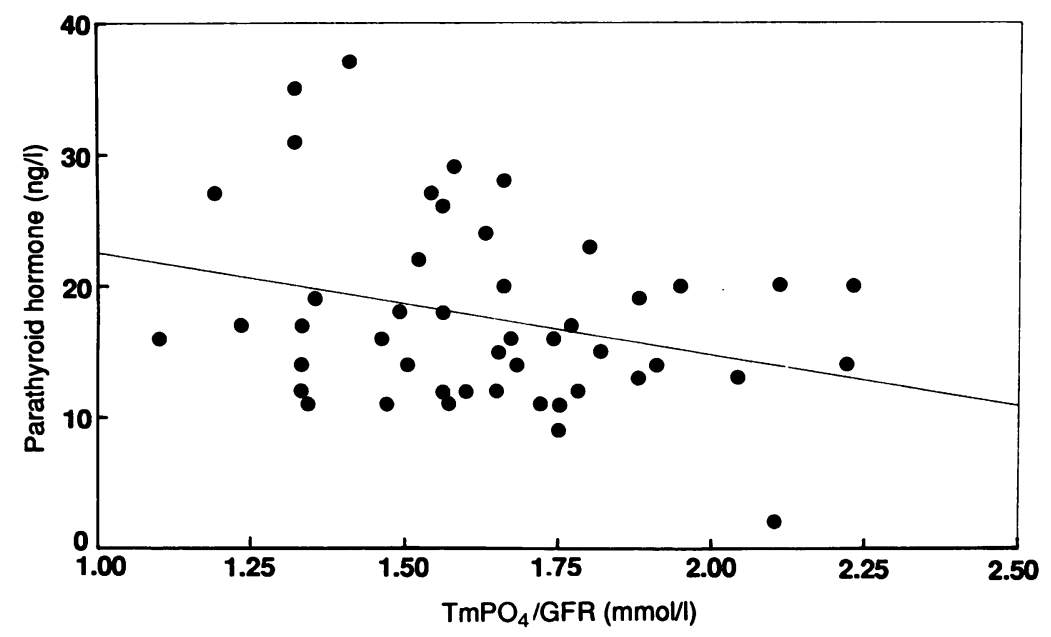

Figure 2 Correlation between the tubular maximum reabsorption rate of phosphate per litre of glomerular filtrate $\left(\mathrm{TmPO}_{4} / G F R\right)$ and intact molecule parathyroid hormone.

that avoided milk products and vitamins. ${ }^{7}$ The upper limit, calculated by adding the arithmetic mean plus two standard deviations, was 0.59 mmol:mmol. Moore et al, who collected random urine samples on 273 predominantly black American children aged 3 months to 16 years on unrestricted diet, quote an upper limit of 0.51 mmol:mmol again based on an arithmetic mean plus two standard deviations. ${ }^{8}$ Kruse et al collected fasting urine samples on 564 German schoolchildren aged 6-18 years who were on an unrestricted diet.9 Their data was log transformed and the results expressed as centiles giving a 97th centile value of $0.49 \mathrm{mmol}: \mathrm{mmol}$. Some of the variation can be accounted for by racial or dietary differences and by the fact that one of the studies was undertaken in non-fasting conditions. ${ }^{8}$ In addition, some of the quoted upper results are based on arithmetic means and standard deviations which are an incorrect method of representing data that is not normally distributed. This would have had the effect of producing lower upper limits. The 97th centile value in our study of $0.69 \mathrm{mmol}: \mathrm{mmol}$ is close to the value of $0.74 \mathrm{mmol}: \mathrm{mmol}$ obtained by Ghazali and Barratt ${ }^{6}$ so it would appear that values of this magnitude can be applied to British children but may not be applicable to other population groups. As in other studies no association with age and sex was demonstrated for calcium and magnesium:creatinine ratios so that a common normal range can be used.

There have been few previous studies that have reported urine magnesium:creatinine ratios in children. Ghazali and Barratt reported an upper limit of normal of $1.95 \mathrm{mmol}: \mathrm{mmol}$ in 29 children studied in the fasting state ${ }^{6}$ whereas Moore $e t a l,{ }^{8}$ using a larger sample of 273 children, report a much lower non-fasting value of $0.54 \mathrm{mmol}: \mathrm{mmol} .{ }^{8}$ However, both these studies have presented values based on arithmetic means. Our study using fasting morning urines gives a 97th centile value of $1.05 \mathrm{mmol}: \mathrm{mmol}$. The same value is obtained if the data is log transformed and the upper $95 \%$ tolerance limit calculated. The only other apparent explanation why the upper limit of normal for magnesium: creatinine ratios in our children should differ from those in the other two studies is because of possible differences in the diets of the children studied.

The calcium and magnesium excretion indices are calculated values that allow for renal function permitting comparison of individuals with different glomerular filtration rates. It is often used as the preferred index in adult studies such as the investigation of familial hypocalciuric hypercalcaemia. Our study has shown a very strong correlation between these indices and the calcium and magnesium:creatinine ratios, which is not surprising as the variation in plasma creatinine concentration in normal children of the age group was small. Thus although in a group of children with normal renal function the excretion indices offer no advantage, the normal values may be of use in the investigation of children with impaired renal function.

It is important to note that in the calculation of the excretion index for calcium or magnesium the plasma creatinine has been expressed in $\mu \mathrm{mol} / 1$. However when calculating clearances or tubular maximums the value of plasma creatinine must be converted to $\mathrm{mmol} / \mathrm{l}$ as urinary creatinine is expressed in these units.

It has been recognised for a long time that the fractional excretion of phosphate and its inverse, the tubular reabsorption of phosphate, are not sensitive measures of renal phosphate handling. The tubular maximum reabsorption threshold for phosphate which corrects for variation in glomerular filtration rate has been regarded as the most suitable index. A nomogram was constructed by Walton and Bijvoet from which a knowledge of the serum phosphate and the tubular reabsorption of phosphate would allow calculation of the tubular maximum ( $\left.\mathrm{TmPO}_{4} / \mathrm{GFR}\right){ }^{10}$ This has been used to calculate normal ranges for $\mathrm{TmPO}_{4} / \mathrm{GFR}$ in children ${ }^{11}$ and infants under 6 months. ${ }^{12}$ Two equations have been derived from the nomogram of Walton and Bijvoet which can be solved by a programmable calculator or computer to simplify calculation of $\mathrm{TmPO}_{4} / \mathrm{GFR}^{5}$

There are some differences seen between our study and other published data on $\mathrm{TmPO}_{4} / \mathrm{GFR}$ in children. ${ }^{11} 12$ Kruse et al demonstrated an inverse correlation between $\mathrm{TmPO}_{4} / \mathrm{GFR}$ and age which was not seen in our study. ${ }^{11}$ This may be due to our smaller sample particularly the low numbers in our sample who were postpubertal where the main fall in $\mathrm{TmPO}_{4} / \mathrm{GFR}$ was seen in their study. Certainly our values are higher than the accepted normal range in adults which is $0.8-1.35 \mathrm{mmol} / 1 .^{10} \mathrm{We}$ have presented our data for different ages but because of the lack of correlation with age we have also presented a common range which may be easier to use in practice. The other main difference seen between our study and that of Kruse et al is that our mean values for $\mathrm{TmPO}_{4} / \mathrm{GFR}$ are significantly lower than theirs, the geometric mean value in our study of $1.67 \mathrm{mmol} / \mathrm{l}$ being equivalent to their mean value seen at age 13 to 14 years. This could be accounted for by racial or dietary differences emphasising the importance of having reference values appropriate for the particular population being studied. Unlike their study we did demonstrate a significant 
inverse correlation between $\mathrm{TmPO}_{4} / \mathrm{GFR}$ and parathyroid hormone which probably reflects the fact that intact molecule parathyroid hormone is a more sensitive assay of parathyroid hormone activity than the predominantly C-terminal assay they employed.

Until recently there have been difficulties in reliably measuring serum parathyroid hormone. Earlier assays that relied on antisera to discrete parts of the hormone, such as the N-terminal, C-terminal, and the mid-molecular region, were not able to distinguish reliably between normals and abnormals. In addition studies have shown an appreciable disparity between circulating concentrations of parathyroid hormone measured by these older immunoassays and biologically active parathyroid hormone measured by a cytochemical bioassay. ${ }^{13}$ New assays have been developed that specifically recognise intact parathyroid hormone, which is the principal bioactive form. ${ }^{14}$ These are sensitive and have the ability to distinguish between normals, patients with primary hyperparathyroidism, and patients with non-parathyroid hypercalcaemia. They are also the most appropriate assay for individuals with chronic renal failure. Although there are data available for adults using these assays, ${ }^{14}{ }^{15}$ there is little information on values in normal children. The adult normal range using the immunoradiometric assay as used in this study is $10-65 \mathrm{ng} / 1$ (Allegro, Nichols Institute). Kruse et al report a normal range of 14-55 ng/l from a control group that included children but they quoted a common range that included people with an age range of 5-43 years without distinguishing between the results obtained from the adults and children. ${ }^{16}$ Our results using the immunoradiometric assay show that the normal range for intact parathyroid hormone is lower in children. The values obtained using this assay, although lower than those found using fragment assays, are probably still higher than those found in sensitive bioassays.

There have been several previous studies using older parathyroid hormone assays in normal children with differing results. Clayton et al found values of parathyroid hormone to be lower in children under the age of 6 years but adult values were found by the age of 8 years. ${ }^{17}$ Arnaud et al found higher than adult values in children under 6 years but lower values in the 6 to 12 year age group. Stark et al, using an assay specific for the C-terminal end of the molecule found values in children up to the age of 16 years to be lower than adults. ${ }^{19}$ It is difficult, however, to compare these studies because of the different parathyroid hormone assays used. Our results resemble those of Stark et al in that the parathyroid hormone concentrations using the intact molecule assay were lower than adult values throughout the 2 to 15 year age group studied. The correlation of $\mathrm{TmPO}_{4} / \mathrm{GFR}$ and intact molecule parathyroid hormone suggests that the former is a reliable parameter of parathyroid function in normal children. The relatively small differences in parathyroid function in children and adults are not likely to be solely responsible for the differences seen in tubular phosphate reabsorption. There may be other influences acting on tubular phosphate reabsorption in children to account for this.

We thank Sue Phillips, Leonie Shapiro, and the department of chemical pathology at St James's University Hospital for performing the laboratory assays, and Mandy Jones for typing the manuscript.

NJ Shaw received financial support from the Yorkshire Kidney Research Fund.

1 Heiliczer JD, Canonigo BB, Bishof NA, Moore ES. Noncalculi urinary tract disorders secondary to idiopathic hypercalciuria in children. Pediatr Clin North Am 1987;34: 711-8.

2 Bulusu L, Hodgkinson A, Nordin BEC, Peacock M. Urinary excretion of calcium and creatinine in relation to age and body weight in normal subjects and patients with renal calculus. Clin Sci 1970;38:601-12.

3 Nordin BEC. Plasma calcium and plasma magnesium homeostasis. In: Nordin BEC, ed. Calcium, phosphate and magnesium metabolism. London: Churchill Livingstone, 1976:190-1.

4 Bijvoet OLM. Indices for the measurement of the renal handling of phosphate. In: Massry SG, Fleisch H, eds. Renal handling of phosphate. New York: Plenum, 1980:1-37.

5 Kenny AP, Glen ACA. Tests of phosphate reabsorption. Lancet 1973;ii: 158.

6 Ghazali S, Barratt TM. Urinary excretion of calcium and magnesium in children. Arch Dis Child 1974;49:97-101

7 Stapleton FB, Noe HN, Jerkins G, Roy S. Urinary excretion of calcium following an oral calcium loading test in healthy children. Pediatrics 1982;69:594-7.

8 Moore ES, Coe FL, McMann BJ, Favus MJ. Idiopathic hypercalciuria in children: prevalence and metabolic characteristics. I Pediatr 1978;92:906-10.

9 Kruse K, Kracht U, Kruse U. Reference values for urinary calcium excretion and screening for hypercalciuria in chil dren and adolescents. Eur $\mathcal{F}$ Pediatr 1984;143:25-31.

10 Walton RJ, Bijvoet OLM. Nomogram for derivation of renal threshold phosphate concentration. Lancet 1975;ii:309-10.

11 Kruse K, Kracht U, Gopfert G. Renal threshold phosphate concentration (TmPO/GFR). Arch Dis Child 1982;57: concent $217-23$.

12 Bistarakis L, Voskaki I, Lambadaridis J, Sereti H, Sbyrakis S. Renal handling of phosphate in the first six months of life. Arch Dis Child 1986;61:677-81.

13 Anonymous. Measuring the PTH level. [Editorial.] Lancet 1988;i:94-5.

14 Brown RC, Aston JP, Weeks I, Woodhead JS. Circulating intact parathyroid hormone measured by a two-site immunochemiluminometric assay. $\mathcal{f}$ Clin Endocrinol Metab 1987;65:407-14.

15 Evans RM, Cooper AJ, Halkett JM, Gunn IR. Intact molecule PTH: suppression with a standard oral calcium load, and analysis of analytical and biological variation in healthy individuals. Ann Clin Biochem 1988:25(suppl 1):176-7.

individuals. Ann Clin Biochem 1988:25(suppl 1):176-7.
16 Kruse K, Kracht U, Wohlfart K, Kruse U. Biochemical markers of bone turnover, intact serum parathyroid hormarkers of bone turnover, intact serum parathyroid hor-
mone and renal calcium excretion in patients with mone and renal calcium excretion in patients with pseudohypoparathyroidism and hypoparathyroidism before
and during vitamin D treatment. Eur F Pediatr 1989;148: and durin 935 .

17 Clayton BE, Jenkins P, Round JM, eds. Paediatric chemical pathology. Oxford: Blackwell Scientific Publications, 1980:122.

18 Arnaud SB, Goldsmith RS, Stickler GB, McCall JH, Arnaud $\mathrm{CD}$. Serum parathyroid hormone and blood minerals Interrelationships in normal children. Pediatr Res 1973;7: 485-93.

19 Stark M, Eisenstein B, Davidovitis M. Parameters for evaluation and correlation of renal phosphate handling and of parathyroid function in children. Nephron 1989;51:478-81. 